\title{
THE CAROTID SINUS REFLEX IN PATIENTS WITH HYPERTENSION
}

\author{
By GEORGE D. GAMMON 1 \\ (From the Johnson Foundation, University of Pennsylvania, and the Medical Clinic of the \\ Hospital of the University of Pennsylvania, Philadelphia)
}

(Received for publication September 23, 1935)

The observation that a state of elevated blood pressure develops in animals after denervation of the carotid sinus and aortic arch (1) has suggested that certain forms of hypertension in man might similarly be due to a failure of the depressor mechanism. Several studies have lent some support to this hypothesis $(2,3,4)$. The evidence may be summarized briefly as follows: direct stimulation of the carotid sinus endings in hypertensive patients by digital pressure over the walls of the sinus causes a marked fall in blood pressure; however, alteration of pressure within the carotid sinus by digital compression and release of the common carotid artery below the sinus produces only minimal or negligible changes in blood pressure or heart rate. The conclusion has therefore been drawn that in hypertension there exists a certain degree of insensitiveness of the carotid sinus endings to their physiologic stimulus, namely changes in intravascular pressure within the sinus. The suggestion, furthermore, has been made that in these patients this defect is, in part at least, responsible for the development of the elevation of blood pressure $(4,5)$.

The desirability of reexamining the observations which are the basis of these claims concerning the etiology of hypertension in man is apparent.

\section{METHODS AND MATERIAL}

On a number of patients with elevated blood pressure the carotid sinus test was performed essentially in the manner described by Mandelstamm and Lifschitz (3). The procedures may be briefly described as follows: with the individual prone, the carotid sinus is compressed against the transverse processes of the vertebrae for a period of 30 to 60 seconds. The common carotid artery is compressed as low in the neck as is possible, attempting to avoid traction on the sinus. The carotid artery was obstructed for periods up to 2

1 Godey and Seegar Fellow in Medicine. minutes. Control observations were made by pressure on an indifferent part of the neck. Simultaneous determinations of blood pressure and pulse rate were made before, during and after such procedures. A sufficient number of observations were made to determine the typical reaction of the individual. Bilateral compression was never employed. Blood pressure was estimated by the auscultatory method; pulse rate, either by counting at the wrist or by plethysmographic recording.

Thirty-one patients are included in the present series. Rejections were made of those in whom, for anatomical reasons, it was impossible adequately to compress the sinus' or the common carotid arteries. The range of systolic pressure levels was 160 to 240 with the majority above 180 ; diastolic levels lay between 80 and 140 , the greater number being above 100 . About half the group were of the so-called essential hypertension type; the other half exhibited hypertension associated with generalized arteriosclerosis. As to age, the majority were in the fifth decade, the rest divided between the third, fourth and sixth decades, except for. one each in the second and seventh decades. Most of the persons were ambulatory. In practically all, complete cardiac compensation was maintained; in many, however, some degree of cardiac damage was evident either in the symptom of angina pectoris, a prior period of cardiac decompensation, or in electrocardiographic changes suggesting myocardial damage.

\section{RESULTS}

In the group of hypertensive individuals studied a fall in blood pressure and pulse rate on direct stimulation of the carotid sinus endings by pressure over the sinus was readily obtained. The average fall in this series was $45 / 24 \mathrm{~mm}$. $\mathrm{Hg}$ on stimulation of the left sinus, and $43 / 20 \mathrm{~mm}$. $\mathrm{Hg}$ on stimulation of the right. The scatter of the observations is listed in Table $\mathrm{I}$. The average 
TABLE I

Fall in blood pressure on compression of carotid sinus

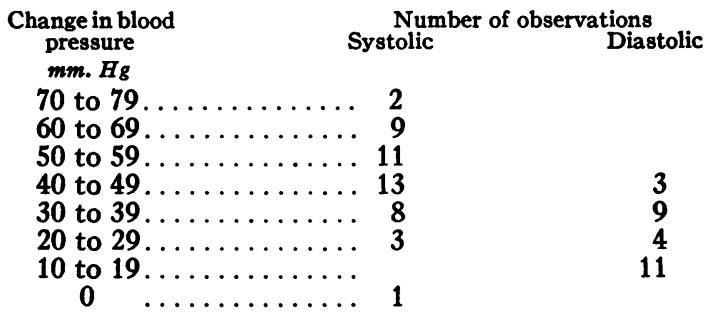

fall in pulse rate was 16 per minute with a range of 0 to 42 . These results are comparable with those of Mandelstamm and Lifschitz who found a drop of $30 \mathrm{~mm}$. $\mathrm{Hg}$ or more in 55 per cent of persons whose systolic pressure was above 180 . Weiss and Baker (6) obtained an average drop of $40 / 18 \mathrm{~mm} . \mathrm{Hg}$ in 42 hypertensive individuals; in their group 78 per cent exhibited a fall of 10 to $105 \mathrm{~mm}$. $\mathrm{Hg}$ in systolic pressure. The average decrease in pulse rate in their series was 8 per minute, the extremes ranging from 4 to 20 . It may be noted that the changes here reported are much more marked than those occurring in normal individuals (6).

In contrast with the results of others, however, $(3,4)$, alterations of pressure within the carotid sinus produced, in this group of patients, significant reflex changes in blood pressure and pulse rate. Lowering of the intrasinusal pressure by obstruction of the left common carotid artery below the sinus resulted in an average rise in pressure of $25 / 18 \mathrm{~mm}$. $\mathrm{Hg}$; obstruction of the right carotid, a rise of $24 / 25 \mathrm{~mm}$. $\mathrm{Hg}$. The average pulse rise was 8 per minute from the left and 6 from the right. The scatter of the observations is listed in Table II.

TABLE II

Rise in blood pressure on compression of common carotid artery

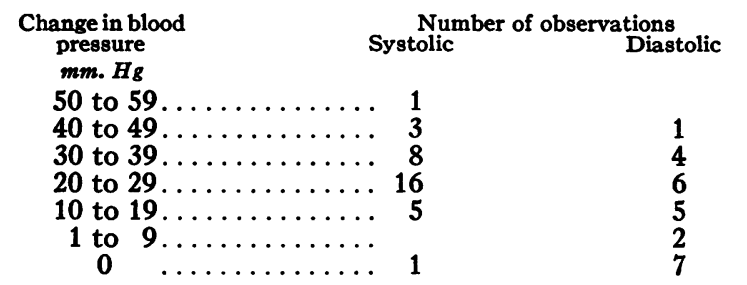

The opposite change in blood pressure, that is, a fall, was induced on release of the obstructed common carotid artery in most cases; in about half, the pressure fell below the control level. The results of this procedure are listed in Table III. The change in pulse rate is minimal and lasts a very short time. However, in 10 instances the first beats after release of the obstructed artery were slower than during the obstruction.

TABLE III

Changes in blood pressure and pulse rate on release of obstructed common carotid artery

\begin{tabular}{|c|c|c|c|}
\hline \multirow{3}{*}{$\begin{array}{l}\text { Range of changes in } \\
\text { blood pressure }\end{array}$} & \multicolumn{3}{|c|}{ Number of observations } \\
\hline & \multicolumn{2}{|c|}{ Change in blood pressure } & \multirow{2}{*}{$\begin{array}{l}\text { Change in } \\
\text { pulse rate }\end{array}$} \\
\hline & Systolic & Diastolic & \\
\hline $\begin{array}{r}\quad m m . H_{g} \\
0 \ldots \ldots \\
-1 \text { to }-9 \ldots \ldots \ldots \\
-10 \text { to }-19 \ldots \ldots \ldots \\
-20 \text { to }-29 \ldots \ldots \ldots \\
-30 \text { to }-39 \ldots \ldots \ldots \\
-40 \text { to }-49 \ldots \ldots \ldots \\
-50 \text { to }-59 \ldots \ldots \ldots \\
-60 \text { to }-69 \ldots \ldots \ldots \\
-70 \text { to }-79 \ldots \ldots \ldots \\
-80 \text { to } \quad \ldots \ldots \ldots\end{array}$ & $\begin{array}{r}1 \\
4 \\
9 \\
6 \\
3 \\
3 \\
11 \\
1 \\
1 \\
2\end{array}$ & $\begin{array}{r}5 \\
1 \\
14 \\
6 \\
3\end{array}$ & $\begin{array}{r}10 \\
10 \\
3\end{array}$ \\
\hline
\end{tabular}

It is thus apparent that in the majority of persons examined, appropriate reflex changes in blood pressure were elicited from alterations of intrasinusal pressure. Exceptions may be listed as follows. In one case in which adequate tests could be made, no effect was observed on compressing either left carotid sinus or carotid artery, although normal results were obtained on the right. In 7 persons a fall in blood pressure rather than a rise resulted from obstruction of the common carotid artery. This result is probably attributable to stimulation of the carotid sinus nerve by traction, rather than to a failure of the sinus to respond to changes in intravascular pressure. Anatomical conditions make this unavoidable in certain instances. In one very nervous patient with essential hypertension no results were obtained, largely due to lack of cooperation on the part of the patient.

In this series there was no significant difference in the reactions obtained from the patients with essential hypertension and the group associated with arteriosclerosis. One gets the impression, 
however, that to induce similar falls in blood pressure, less digital pressure is required over a sclerotic sinus than over one which is soft and pliable.

In passing, reference should perhaps be made to certain findings not directly related to the question under consideration. In several persons blood pressure could not be determined over long periods of time due to disappearance of all sounds over the artery below the obstructing cuff. This disappearance was not necessarily accompanied by a low level of general blood pressure, for determinations taken in the opposite arm revealed normal sounds. In one person swallowing would initiate the disappearance of sounds without any fall in pulse rate. Long compression of the artery seemed to favor the development of this phenomenon.

One patient in this series, hypertensive at times, when examined, showed a blood pressure of $140 / 70 \mathrm{~mm} . \mathrm{Hg}$. Obstruction and release of the common carotid arteries gave a typical response. Stimulation of the carotid sinus of one side, however, caused a fall in blood pressure to $100 \mathrm{~mm}$. $\mathrm{Hg}$ and was accompanied by fainting and slight convulsive movements. Similar reactions in normal individuals have been reported by Weiss and Baker (6).

\section{Mechanism of the fall in blood pressure on stimulation of the sinus nerves}

It is of interest to know whether the fall in blood pressure in hypertensive individuals as a result of stimulation of the carotid sinus endings is due to generalized vasodilatation as well as diminished cardiac output. Although our results give no direct evidence on the point, it seems likely that vasodilatation is partly responsible for the following reasons. No correlation was noted between the fall in blood pressure and the change in pulse rate. In many instances maximum change in blood pressure was accompanied by little or no alteration in pulse rate. This finding is in agreement with the results of others (3). Further, Mandelstamm and Lifschitz found that atropinization sufficient to abolish cardiac slowing did not prevent the fall in blood pressure due to stimulation of the carotid sinus nerves in hypertensive patients. This evidence, while indirect, again suggests that vasodilatation occurs in such individuals as well as in normal persons.

\section{DISCUSSION}

The fact that a fall in blood pressure is obtainable in hypertensive patients on stimulation of the carotid sinus demonstrates that the depressor arc in them is capable of functioning in all its parts including the efferent motor nerves and the muscle of the vessel wall. Responses induced by occlusion and release of the common carotid arteries indicate that the carotid sinus nerve endings are sensitive to changes in intravascular pressure, contrary to the observation of others. The only way in which the hypertensive differs from the normal is in a somewhat exaggerated degree of reaction. It is possible the changes observed following variations in intrasinusal pressure here reported differ from those of other observers because a careful selection was made of patients on the basis of easy compressibility of carotid arteries. Also it is possible somewhat longer compression of the common carotid arteries was carried out here than by others for this was found necessary to evoke the reflex changes described.

Why then, if the carotid sinus nerve endings are functioning in hypertensive individuals is the pressure not reduced to a normal level? An answer to this question can not be given on the basis of our present knowledge. One possibility to be considered, however, concerns adaptation of the endings of the carotid sinus to sustained high levels of blood pressure. Bronk (7) has observed a maintained discharge in single fiber preparations of carotid sinus nerves during perfusion of the sinus at high pressures for periods of minutes. Furthermore, Larrabee (8) has observed in cats a continued depressor reflex during perfusion of the sinus at high pressure levels for periods as long as 20 minutes. Nothing is known, however, concerning adaptation of the endings to pressures maintained for days, and it is not inconceivable that the sensory discharge of the carotid sinus eventually declines due to adaptation of the endings at these maintained high pressures. From this viewpoint, with the blood pressure stabilized about the new level, the sinus would still operate to smooth out sudden changes. A similar possibility of adaptation occurs in the 
other portions of the arc involved in the depressor reflex. (See Bronk et al. (14))

The interpretation of the results of this study, namely that the carotid sinus nerves are functioning normally in hypertensive patients of the type examined, taken together with other recent observations in such cases supply some suggestive implications as to the nature of the process whereby the hypertension is developed. Interruption of the nerve supply of large vascular areas in persons with high blood pressure will lower the pressure to normal levels. For example, the fall in blood pressure which occurs in these patients after the induction of spinal anesthesia, equals or is greater than that obtained in normal persons (9, 10). This observation was confirmed in two of the present series. Furthermore, the claim has been made that surgical denervation of a considerable vascular area will result in a persistent drop in the blood pressure in such patients, (11, $12,13)$, though further long-time observations on the point seem desirable. If, then, denervation of blood vessels, by one of the methods mentioned above, lowers the blood pressure of hypertensive patients to normal levels, and if the carotid sinus mechanism in these patients is functioning normally, the suggestion arises that the modus operandi of human hypertension, whatever the etiology, should be sought for either in some part of the depressor reflex arc other than the sensory discharge of the carotid sinus, or in an abnormal reaction of the vessels to the tonic vasoconstrictor impulses.

\section{SUMMARY}

In a study of 31 patients with hypertension of either the essential type or that associated with arteriosclerosis, the carotid sinus nerve endings were found, in accordance with other. observers, to cause a depressor reflex when stimulated directly. The response to changes in intravascular pressure within the sinus, contrary to the findings of others, was in the direction usually obtained in normal persons. These observations indicate that a failure of the carotid sinus mechanism is not the cause of hypertension in these patients. The significance of these findings is discussed in relation to nervous factors concerned in hypertension.

\section{BIBLIOGRAPHY}

1. Dautreband, L., Essai de thérapeutique médicamenteuse de l'hypertension expérimentale. Compt. rend. Soc. de biol., 1933, 111, 1038.

2. Regniers, $P$., Le sinus carotidien en clinique. Rev. belge sc. méd., 1930, 2, 601.

3. Mandelstamm, M., and Lifschitz, S., Die Wirkung der Karotissinusreflexe auf den Blutdruck beim Menschen. Wien. Arch. f. inn. Med., 1932, $22,397$.

4. Mies, H., Experimentelle und klinische Untersuchungen über den Entzügelungshochdruck. Ztschr. f. klin. Med., 1932, 120, 613.

5. Heymans, C., Bouckaert, J. J., and Regniers, P., Le sinus carotidien. G. Doin et Cie. Paris, 1933.

6. Weiss, S., and Baker, J. P., The carotid sinus reflex in health and disease. Its role in the causation of fainting and convulsions. Medicine, 1933, 12, 297.

7. Bronk, D. W., Personal communication.

8. Larrabee, M. G., Personal communication.

9. Berg, A., Blood pressure in hypertonics during spinal anesthesia. Acta med. Scandinav., 1932, Supp. 50, 299.

10. Hyman, A. S., Spinal anesthesia in hypertension. J. A. M. A., 1933, 101, 1410.

11. Adson, A. W., and Brown, G. E., Malignant hypertension. Report of case treated by bilateral section of anterior spinal nerve roots from the sixth thoracic to the second lumbar, inclusive. J. A. M. A., 1934, 102, 1115.

12. Page, I. H., and Heuer, G. J., A surgical treatment of essential hypertension. J. Clin. Invest., 1935, $14,22$.

13. Peet, Max M., Splanchnic section for hypertension. Univ. Hosp. Bull., Ann Arbor, 1935, 1, 17.

14. Bronk, D. W., Ferguson, L. K., and Solandt, D. Y., Inhibition of cardiac accelerator impulses by the carotid sinus. Proc. Soc. Exper. Biol. and Med., 1934, 31, 579. 